\title{
Marx em tempos de MEGA: os planos e o plano de $O$ Capital
}

\author{
Leonardo Gomes de Deus \\ Professor - Universidade Federal de Ouro Preto (UFOP) \\ Endereço: Rua do Catete, 166 - Mariana/MG - Brasil \\ CEP: 35420-000 - E-mail: dedeus@icsa.ufop.br \\ Recebido em 27 de fevereiro de 2013. Aceito em 22 de setembro de 2014.
}

\section{Resumo}

Com a publicação de textos inéditos de Marx, tem sido possível avaliar com maior precisão seu itinerário intelectual. O presente artigo investiga os momentos que conduziram o autor a um plano consistente e logicamente articulado para O Capital, em meio à redação de uma série de planos e manuscritos. Utilizam-se para tanto os Grundrisse, o Manuscrito de 1861-1863 e manuscritos redigidos nos anos seguintes, recentemente publicados. Explora-se assim uma perspectiva sobre os planos de redação da obra econômica de Marx, diferente daquela formulada por Roman Rosdolsky.

\section{Palavras-Chave}

O Capital. Karl Marx. Marx-Engels. Gesamtausgabe. Roman Rosdolsky.

\begin{abstract}
The publishing of the unknown manuscripts by Karl Marx has made possible a more detailed analysis of his intellectual legacy. This paper tries to show how and when Marx was able to establish a logical plan for his work Das Kapital. For this matter, the paper examines the manuscripts written between 1857 and 1865, some of them recently published in the new MEGA edition. Those writings may offer a different point of view from Roman Rosdolsky among others on the many plans Marx wrote for his economical work.
\end{abstract}

\section{Keywords}

Das Kapital. Karl Marx. Marx-Engels. Gesamtausgabe. Roman Rosdolsky.

\section{JEL Classification}

B14. B31. B41.

\footnotetext{
- O autor agradece ao CNPq pelo financiamento da pesquisa.
} 


\section{Introdução}

A questão sobre os planos para a redação de O Capital só se transformou num verdadeiro problema muito recentemente. Quando de sua elaboração, por Rosdolsky, ${ }^{1}$ era apenas uma curiosidade histórica. Nos anos recentes, no entanto, transformou-se num duplo problema. Em primeiro lugar, diz respeito à fidelidade com que Engels levou a termo a publicação póstuma dos livros segundo e terceiro da obra, a partir dos diversos manuscritos legados por Marx. Em segundo lugar, diz respeito à completude categorial, lógica, da obra econômica marxiana, se teria consistência em seu arremate, ao menos para seu autor. Com efeito, detratores de Marx chegaram a afirmar que ele teria desistido de sua obra num dado momento. Basta citar, no nível prosaico, a afirmação de Ludwig von Mises (1995: 80) de que Marx teria adiado sine die a publicação dos livros restantes de $\mathrm{O}$ Capital ao tomar contato com os marginalistas de sua época. Esse segundo problema é exatamente o objeto do presente artigo.

A crítica da economia política marxiana não nasceu pronta, nem se fez em pouco tempo. Sua primeira publicação importante, de 1859, ocorreu quinze anos depois da primeira formulação, qual seja, os Manuscritos de 1844, depois de muitos anúncios e adiamentos. E somente em 1867, com a publicação do livro primeiro de O Capital, pode-se falar da plena maturidade dessa crítica. No período de vinte e três anos, Marx elaborou uma série de planos para sua obra, anunciou diversos formatos e redigiu diversos esboços e materiais preparatórios, além das anotações de leitura. O que restou desses esboços está publicado na segunda seção da nova MEGA, seção cuja edição se completou em setembro de 2012. Diante disso, resultados interessantes podem ser obtidos, nem sempre novos, mas sempre mais profundos, sendo o presente artigo a tentativa de explorar um aspecto dentre tantos: a existência de um plano consistente para $\mathrm{O}$ Capital e o momento em que foi estabelecido. Ou por outra, analisar a completude da obra, diante do fato de sua publicação parcialmente póstuma, realizada por Engels.

1 O livro utilizado aqui foi publicado pela primeira vez, postumamente, em 1968. 
O que se pretende mostrar aqui é o desenvolvimento de uma lógica categorial para seu próprio autor, durante um período específico de sua atividade criadora. Tenta-se captar o momento em que o plano de O Capital ganhou consistência suficiente a permitir o passo seguinte, a redação propriamente dita. Com efeito, a partir dos anos de 1861 a 1863, segundo a hipótese aqui desenvolvida, Marx possui um plano minimamente coerente para que, nos anos seguintes, possa redigir não só o livro primeiro de $\mathrm{O}$ Capital, mas também uma série de manuscritos que serão utilizados por Engels na edição dos livros segundo e terceiro.

A tarefa envolve certo risco, similar ao do jurista que tenta pesquisar a mens legislatoris, em lugar da mens legis, procedimento geralmente correto. Estabelecer como se formou e desenvolveu a estrutura de $\mathrm{O}$ Capital é algo arriscado, sobretudo em razão de que Marx, durante cada nova redação, modificava ou abandonava tematizações previamente estabelecidas, não havendo garantias de que os livros segundo e terceiro de O Capital seriam efetivamente publicados tal como se encontravam nos manuscritos. O que se pode fazer aqui, diante disso, é analisar os textos em sua cronologia e, a partir de seu espírito, verificar a construção marxiana, o método de pesquisa em direção ao método de exposição, ou por outra, a construção da lógica categorial. Assim, para além dos diversos planos formulados ao longo dos anos, há que se buscar o plano lógico subjacente à tematização marxiana: busca-se ir além da discussão realizada por Rosdolsky (2001), conferindo-lhe nova resolução e novos elementos.

Além desta introdução e das considerações finais, o texto é composto de mais três seções, uma relativa aos planos elaborados entre 1857 e 1859, outra dedicada ao Manuscrito de 1861-1863 e a leitura realizada por Rosdolsky e, finalmente, uma seção dedicada aos manuscritos imediatamente posteriores a 1863. 


\section{Os planos de redação nos anos de 1857 a 1859: a revolução metodológica}

Os planos de redação de $\mathrm{O}$ Capital devem ser subsumidos à questão mais importante: a formação de um plano lógico, capaz de fornecer a gênese das categorias que, na economia política tradicional, são apreciadas de modo extrínseco. Como afirma Reichelt (1970: 16), "Enquanto a economia política burguesa é caracterizada em geral por captar as categorias exteriormente, Marx insiste numa dedução rigorosa da gênese dessas formas [econômicas - LGD] - um objetivo que remete à crítica de Hegel da filosofia transcendental kantiana." Há que se ressaltar, porém, que, em Marx, essa construção se dá a partir de Hegel e, ao mesmo tempo, supera sua construção. Localizar nos escritos de Marx esse ponto de inflexão é o propósito deste artigo: encontrar o plano lógico a partir dos planos de redação. Tenta-se encontrar a lógica categorial a partir da construção do "método de exposição", formulado, por sua vez, a partir do "método de pesquisa". No caso dos planos de redação, cumpre dizer que se referem, via de regra, a material elaborado ou em elaboração, uma projeção futura do que já havia conquistado em sua pesquisa. Discutir uma coisa sem a outra, portanto, empobrece a análise, mas é a única possibilidade, detectar os momentos em que Marx considerou a pesquisa suficientemente completa para uma nova elaboração, para a exposição propriamente dita. Muitas vezes, nos anos de 1857 a 1863, tratou dessa questão, justamente porque foram anos de intensa pesquisa.

De fato, os anos referidos correspondem a período de grande elaboração teórica para Marx, com a redação dos Grundrisse (1857/58) e do chamado Manuscrito de 1861-1863, além de ter sido publicada a obra Para a crítica da economia política em 1859. Nesse período, pode-se dizer, Marx formulou alguns dos principais aspectos de sua obra econômica, sua teoria do valor, a tematização sobre a mercadoria, a teoria do mais-valor, dentre muitos outros. Não se trata de analisar aqui, evidentemente, os aspectos cruciais desse desenvolvimento, mas tão somente aqueles que dizem respeito à formulação dum plano categorial por seu autor.

Assim, em primeiro lugar, cabe citar a carta a Lassale de vinte e dois de fevereiro de 1858. Próximo da conclusão da redação dos Grundrisse, Marx anuncia um plano para sua obra: 
O trabalho de que se trata primeiramente é crítica das categorias econômicas, ou, if you like, o sistema da economia burguesa apresentado criticamente. É ao mesmo tempo exposição do sistema e sua crítica por meio da exposição. Não está claro para mim quantas páginas impressas o todo conterá. Se eu tivesse tempo, calma e meios para completá-lo, antes de entregá-lo ao público, eu o faria mais conciso, já que sempre gostei do método de condensação. (...) O conjunto se divide em seis livros: 1. Do capital (contém alguns capítulos preliminares). 2. Da propriedade da terra. 3. Do trabalho assalariado. 4. Do Estado. 5. Comércio exterior. 6. Mercado mundial. (Briefe über das Kapital, 62)

Em carta a Engels de dois de abril do mesmo ano, depois de anunciar o mesmo plano, Marx diz:

I. Capital se subdivide em 4 seções: a) capital en général (esse o tema do primeiro fascículo). b) a concorrência ou a ação recíproca de múltiplos capitais. c) crédito, onde o capital aparece como elemento universal frente aos capitais individuais. d) o capital por ações como a forma mais perfeita (que resulta no comunismo), juntamente com todas as suas contradições. (Briefe über das Kapital, 68)

Esse plano seria o marco inicial, o ponto de partida a sofrer alterações severas posteriormente. Cabe apontar ainda algumas noções que Marx formulou no próprio corpo dos Grundrisse, procedimento que será encontrado também nos manuscritos seguintes, qual seja, de elaborar o plano de sua obra no curso da própria exposição. Com efeito, em dois momentos se detém na formulação de um plano geral de sua obra econômica. A primeira, na abertura da seção "valor de troca que surge da circulação". Ele diz: 
I.1 Conceito geral de capital - 2) Particularidade do capital: Capital circulant. Capital fixe. (Capital como meios de subsistência, como matéria-prima, como instrumento de trabalho.) 3) O capital como dinheiro. II. 1) Quantidade de capital. Acumulação. - 2) O capital que mede a si mesmo. Lucro. Juro. Valor do capital; isto é, o capital em diferença de si como juro e lucro. 3) A circulação dos capitais. $\alpha$ ) Troca de capital com capital. Troca de capital com renda. Capital e preços. $\beta$ ) Concorrência dos capitais. $\gamma$ ) Concentração de capitais. III. O capital como crédito. IV. O capital como capital por ações. V. O capital como mercado monetário. VI. O capital como fonte da riqueza. O capitalista. Em seguida, a propriedade da terra deve ser considerada. Depois disso, trabalho assalariado. Pressuposto aos 3, o movimento dos preços, como a circulação então o determina em sua totalidade interna. Por outro lado, as 3 classes já que a produção está posta em suas 3 formas fundamentais e pressupostos da circulação. Então, o Estado. (Estado e sociedade civil. - Os impostos, ou a existência da classe improdutiva. - A dívida pública. - A população. - O Estado em direção ao exterior: colônias. Comércio exterior. Câmbio. Dinheiro como moeda internacional. - Finalmente, o mercado mundial. Domínio da sociedade civil sobre o Estado. As crises. Dissolução do modo produção e forma social baseados no valor de troca. Trabalho individual realmente posto como social e vice-versa. (MEGA II/1.1, 187).

Essas formulações serão o plano que, ao longo dos anos seguintes, sofrerá diversas modificações, sem mencionar aquelas relativas à seção do dinheiro. Interessante que, poucas páginas adiante, Marx reelabora esse plano, na seção do capital, a partir da lógica hegeliana. $\mathrm{Na}$ seção sobre troca entre capital e trabalho, encontra-se a seguinte passagem: 
Capital. I. Universalidade: 1) a) devir do capital a partir do dinheiro. b) capital e trabalho (mediando-se pelo trabalho estranhado). c) os elementos do capital decompostos em sua relação com o trabalho (produto, matéria-prima, instrumento de trabalho). 2) Particularização do capital: a) capital circulante. Capital fixe. Circulação do capital. 3) $A$ singularidade do capital. Capital e lucro. Capital e juro. O capital como valor, diferenciando-se de si como juro e lucro.

II. Particularidade: 1) Acumulação dos capitais. 2) Concorrência dos capitais. 3) Concentração dos capitais (diferença quantitativa do capital ao mesmo tempo tanto qualitativa quanto como medida de sua grandeza e atuação.

III. Singularidade: 1) O capital como crédito. 2) O capital como capital em ações. 3) $\mathrm{O}$ capital como mercado monetário. No mercado monetário, o capital é posto em sua totalidade; ali, ele é determinador de preços, dador de trabalho, regulador da produção, numa palavra, fonte da produção (...). (MEGA II/1.1, 199).

Além da afiliação hegeliana dessa sequência, é fundamental também a constatação marxiana, cedo ainda na obra, de que não seria suficiente a determinação, a distinção do capital como capital em geral face ao dinheiro, apontado ali em sua universalidade, ou caráter geral. Ao identificar o capital como o conceito e seus momentos, Marx constata exatamente a necessidade de instâncias analíticas que, num certo momento, também levem em consideração o capital em sua particularidade, acumulação, concorrência e concentração. No Manuscrito 1861-1863, esses níveis dialéticos serão novamente retomados. Importa dizer aqui que os Grundrisse não são e não podiam ser um sistema fechado, pois Marx ainda não havia nem sequer estabelecido o conteúdo completo e rico de determinações que seria O Capital. Parafraseando Hegel, a filosofia (lógica) só aparece ao final. Assim, conquanto a orientação desse plano lógico não seja rígi- 
da, deixou claro para Marx as diversas instâncias a determinar, razão pela qual, por várias vezes ao longo dos Grundrisse, situou determinada categoria em outra seção, ainda por escrever.

Além disso, nos Grundrisse, Marx começa a absorver sua tematização por aquela do próprio capital, até abandonar o plano exposto nas cartas citadas acima. Por isso, depois da enumeração das categorias do capital, Marx mostra como, progressivamente, o capital transforma a agricultura, tornando-se "criador da agricultura moderna", que impregna a propriedade da terra e cria ali as relações capitalistas de produção. Ao mesmo tempo, esse processo se dá com a criação do trabalho assalariado, na acumulação primitiva. Essa sistematização permite afirmar um dos motivos do abandono do supracitado projeto de seis livros: embora seja trabalho acumulado e objetivado, ainda que dependa da atuação do trabalho vivo para se valorizar, o capital é o verdadeiro motor da sociabilidade moderna, numa relação invertida, perversa, em que transforma trabalho e terra, em suma, toda a objetividade, em elementos de sua existência processual, de sua junção de produção e valorização, a envolver toda a vida social. Por isso, somente no momento último, na quintessência da sociabilidade do capital, a saber, no mercado monetário, no capital a juros, o capital se manifestará em sua plenitude, ao mesmo tempo em que apaga por completo sua origem. Explicar esse desenvolvimento significa, de imediato, abordar a situação do trabalho e da propriedade fundiária. É o que Marx explica mais adiante:

O $3^{\circ}$ momento a desenvolver na formação do conceito de capital é a acumulação primitiva frente ao trabalho, portanto, também o trabalho desobjetivado da acumulação. O primeiro momento parte do valor como proveniente da circulação e a pressupô-la. Era o conceito simples de capital; o dinheiro, tal como era determinado até o capital; o segundo momento parte do capital como pressuposto da produção e seu resultado; o terceiro momento supõe o capital como unidade determinada da circulação e produção. Há que se diferenciar entre acumulação dos capitais; ela pressupõe capitais; a relação do capital como existente e supõe, portanto, também sua vinculação com o trabalho, preços (capital fixe e circulant). Juro e 
Lucro. O capital, porém, para se tornar, supõe certa acumulação; que já se encontra em oposição autônoma do trabalho objetivado contra o vivo; na existência autônoma dessa oposição. Essa acumulação, que é necessária para o devir do capital - como um momento - que está contida em seu conceito, deve ser diferenciada essencialmente da acumulação do capital que se tornou capital, onde já devem existir vários capitais. (MEGA II/1.1, 236).

Essas duas citações mostram como, no curso da análise, aos poucos se insinua a articulação de $\mathrm{O}$ Capital. Também mostram o limite dos Grundrisse quando tomados em seu conjunto. De fato, Marx partiu do dinheiro, em cuja exposição também tratou da mercadoria e, sobretudo, do valor. Ali, o valor de uso assumiu sua importância e adquiriu significado próprio, autônomo. Em seguida, há o capítulo sobre o capital, a partir da circulação do dinheiro, a troca com o trabalho - que, ao longo do texto, passa a se diferenciar de capacidade de trabalho - o processo de produção e o mais-valor. Logo em seguida, porém, a análise se desloca para a questão do lucro, e a referência aos múltiplos capitais se impõe, além da questão da circulação do capital. Conquanto não seja necessária à exposição, Marx desenvolve as formas pré-capitalistas, para então retornar ao circuito do capital, toda a temática do livro II de O Capital, ainda que de modo indicativo. Ao logo desse percurso, inegavelmente, diversas questões afloram, constituindo a maior parte do corpo temático da obra a ser efetivamente publicada por Marx e editada por Engels. No entanto, o método de exposição ainda não estava consolidado e cada passo, nos Grundrisse, representa ao mesmo tempo um esforço de sistematização, sem produzir o resultado esperado.

Pode-se considerar essa "crise metodológica" pela leitura da Introdução, ela mesma inacabada. ${ }^{2}$ Marx abandonou essa introdução porque os resultados têm de ser demonstrados e não expostos $a$ priori. Combate ali as "robinsonadas", o individualismo metodológico que se tornaria dominante século e meio depois, cujo sintoma que mais lhe causava incômodo era a abstração do caráter histórico, localizado da sociedade capitalista, cujas leis são eternizadas por parte da economia política, ao menos a economia de seu tempo. Embora

\footnotetext{
2 Esta exposição sobre a Introdução segue aquela de Chasin (2009).
} 
seja necessário abordar a "produção em geral", na medida em que é uma "abstração razoável". Por outro lado, porém, a economia política adota um procedimento sub-reptício a respeito: "A produção deve antes - ver, por exemplo, Mill - ser apresentada como em distinção da distribuição etc., como limitada pelas eternas leis naturais independentes da história." (MEGA II/1.1, 24). Com isso, a relação real - que Marx trata de explicitar em sua obra - desaparece entre essas duas instâncias. Depois de avaliar essa separação e mostrar exatamente os vínculos entre produção, distribuição, troca e consumo, Marx formula sua concepção de método. Ele diz: "Parece ser correto começar com o real e o concreto, o pressuposto real, assim, por exemplo, na economia, com a população que é a base e o sujeito de todo o ato de produção. Isso se mostra falso, porém, com observação atenta. A população é uma abstração, se, por exemplo, excluo as classes em que se compõe." (MEGA II/1.1, 36). Afinal, trata-se de "uma concepção caótica dum todo", donde se parte até chegar a "conceitos sempre mais simples". A partir daí, o todo pode ser recomposto, desta feita numa "totalidade de muitas determinações e relações". Essa segunda parte foi, na verdade, o procedimento da economia política no século XVIII, método cientificamente correto, que parte de categorias simples e as subsume no pensamento:

O concreto é concreto porque é a concentração de muitas determinações, portanto, unidade de diversos. No pensamento, por isso, aparece como processo de concentração, como resultado, não como ponto de partida, embora ele seja $o$ ponto de partida real e, por isso, também o ponto de partida da observação e da concepção. (Ibidem).

Ao final dos Grundrisse, Marx trata exatamente de pensar a exposição de sua obra, que partira do dinheiro para tratar do capital em geral, alcançar esse concreto pensado. Em toda a obra, as diversas instâncias foram expostas, mas ainda estavam sendo construídas. Hegelianamente, por exemplo, quando Marx celebra, em carta a Engels de janeiro de 1858, ter demolido a teoria do lucro, dentre outras tantas aquisições, ao mesmo tempo, tinha consciência da necessidade de reiniciar a redação. Por isso, em carta a Lassale, de 
doze de novembro de $1858,{ }^{3}$ afirma que a questão de forma ainda era a mais importante, já que dispunha de todo o material necessário. Os Grundrisse representam exatamente um salto qualitativo no pensamento marxiano, uma mudança de fase, mas que seu próprio autor tratou de dissolver, suprassumir, nos momentos seguintes. Ironicamente, a última página do manuscrito constitui precisamente o prenúncio do que viria. Cabe trazê-la à colação para mostrar o momento em que Marx reinicia a redação, sob o título de "l. Valor", trecho que se interrompe abruptamente na segunda página:

A primeira categoria na qual a riqueza burguesa se apresenta é a mercadoria. A mercadoria mesma aparece como unidade de duas determinações. Ela é valor de uso, isto é, objeto de satisfação de qualquer sistema de necessidades humanas. Esse é seu lado material, que as épocas mais díspares da produção podem ter em comum e cujo exame, portanto, está além da economia política. $\mathrm{O}$ valor de uso recai em seu domínio na medida em que é modificado pelas modernas relações de produção, ou, por outro lado, intervém modificando-as. (...) Em verdade, porém, o valor de uso da mercadoria pressuposto dado - a base material na qual uma relação econômica determinada se apresenta. (...) Como o valor de uso se transforma em mercadoria? Portador do valor de troca. Embora unidos imediatamente na mercadoria, valor de uso e valor de troca se separam imediatamente também. Não apenas o valor de troca aparece determinado pelo valor de uso, mas, sobretudo, a mercadoria só se torna mercadoria, só se realiza como valor de troca, na medida em que seu possuidor não se comporta face a ela como valor de uso. É somente por meio de sua alienação, sua troca por outra mercadoria, que ele se apropria de valores de uso. (...) etc. (MEGA II/1.2, 740).

3 Briefe über das Kapital, p. 75. 
Alguns meses depois, em novembro de 1858, Marx se lançaria à rápida redação de Para a Crítica da Economia Política, súmula e ordenação de parte dos desenvolvimentos dos Grundrisse, ponto de chegada e ponto de partida, num nível mais elevado. Nesse livro, publicado em 1859, Marx opera uma autêntica revolução metodológica, iniciando a exposição pela mercadoria, categoria mais elementar e que encerra a totalidade em si mesma. Com isso, Marx sintetiza todo o itinerário precedente, a respeito de valor e dinheiro, encontrando o método de exposição que buscara. Em poucos momentos aparecem relações sociais, menos ainda de produção. Todo o desenvolvimento parece se dar entre coisas, culminando com a circulação internacional do dinheiro. Esse método foi pensado precisamente para expressar o caráter fetichista da sociedade capitalista, em que a aparência é expressão real, mas invertida, da essência, ela mesma invertida de fato. Assim, a mercadoria, unidade elementar aparente da riqueza, ao final, acaba por ser subsumida a seu valor, tornando-se veículo do trabalho objetivado. Tal aquisição acompanhará todo o desenvolvimento a seguir, quando Marx se lançar à redação do Manuscrito de 1861-1863.

A mudança de postura é nítida, podendo ser lida nos manuscritos subsequentes à Crítica de 1859. Diante disso, antes de se lançar ao manuscrito de 1861, Marx redige mais um plano, assim formulado: "I) O processo de produção do capital, com as seções 1) Transformação do dinheiro em capital, cujas subseções são $\alpha$ ) Transição, $\beta$ ) Troca entre mercadoria e capacidade de trabalho, $\gamma$ ) Processo de trabalho, $\delta$ ) $\mathrm{O}$ processo de valorização; 2) $\mathrm{O}$ mais valor absoluto; 3) O mais-valor relativo, com as subseções $\alpha$ ) Cooperação das massas; $\beta$ ) Divisão do trabalho; $\gamma$ ) Maquinaria; 4) A acumulação primitiva; 5) Trabalho assalariado e capital; II) A circulação do capital; III) Capital e lucro; Miscelânea. (MEGA II/2, 256)". ${ }^{4}$ No início do Manuscrito de 1861-1863, é esse plano que Marx parece seguir, esse o ponto de partida do texto que se examina a seguir. Cabe ressaltar, pela estrutura do plano, que Marx ainda trabalharia então com a hipótese dos seis livros.

4 Segundo o editor do texto, esse plano pode ter sido redigido em 1861, mas também em 1859. Chamamos de "plano de 1861" porque é a partir dele que Marx inicia a redação, em 1861, do novo manuscrito. 


\section{Plano de redação e lógica categorial: o Manuscrito de 1861-1863}

Quando se fala do Manuscrito de 1861-1863, ${ }^{5}$ frequentemente se destaca o plano que encerra, já em suas páginas finais, como prova de sua importância na formação do pensamento econômico de Marx. Esse destaque se deveu a Kautsky, dos poucos a ler o manuscrito inteiro durante mais de cem anos, que editou o texto, selecionando apenas o material correspondente ao que pensava ser o livro quarto de O Capital, o que mostra o objetivo das edições da obra marxiana do período, ainda sob a perspectiva estabelecida por Engels e, em parte, pelo próprio Marx. Kautsky defendia que Marx estabeleceu ali o plano definitivo de $\mathrm{O}$ Capital, já redigida parte significativa do livro quarto, portanto. Rosdolsky (2001: 31), que não teve acesso ao manuscrito inteiro, demonstra o completo equívoco dessa análise. Para ele, não há grandes novidades no plano de 1863 face ao plano de 1861, e seria mero desenvolvimento dos planos anteriores, sem ruptura significativa.

Não se pode discordar dessa percepção, mas há que se lhe opor certo reparo. Em primeiro lugar, cabe demonstrar que o itinerário temático do Manuscrito de 1861-1863 encerra outro plano, efetivamente decisivo: o encadeamento, ainda que provisório e desprovido de rigor, dum conjunto de categorias que permitirá a Marx redigir, até 1867, a primeira versão integral do livro primeiro, além de esboços realmente consistentes dos demais. Na exposição que efetua, Rosdolsky supõe que os planos de Marx eram seguidos na redação de modo bastante fiel. Bem ao contrário, Marx não elaborou dois planos, mas incontáveis, vários deles mencionados aqui. Além disso, os planos são sempre formulados por ele de modo ex post, são um resultado do material produzido, geralmente lançado no meio da redação; a exposição emerge, natural e diretamente, como consequência da pesquisa, por outro lado, a redação era também parte do método de pesquisa marxiano. Assim ocorreu nos Grundrisse, também ocorre aqui. Quando, em 1865 ou 1866, Marx redige o plano que Rosdolsky reputa, com justiça, de definitivo, ${ }^{6}$ já redigiu o manuscrito principal do livro segundo, um manuscrito significativo do livro terceiro, além de todos os esboços do livro primeiro, restando apenas o manuscrito

5 Para uma descrição da estrutura e dos temas do Manuscrito, cf. a apresentação da tradução brasileira (2010).

6 Trata-se de constatação óbvia, já que esse plano descreve exatamente a divisão definitiva dos livros tal qual conhecemos, além de um livro quarto, para a história da teoria. Está descrito na carta a Kugelmann de 13 de outubro de 1866. 
redacional, que destruiu. Embora a redação não caminhe às cegas, em nenhum manuscrito, Marx estabelece $a$ priori um sumário de redação e o conduz até a conclusão, qualquer que seja o manuscrito que se examine. ${ }^{7}$ Quando o faz, o plano sofre permanentes modificações até ser bastante descaracterizado. Um plano inovador é a consolidação da pesquisa passada, a proposta da exposição do complexo pensado, portanto, o resultado de conclusões inovadoras.

Em segundo lugar, algumas questões da leitura de Rosdolsky do plano de 1863 merecem consideração. O plano está lançado ao final do caderno XVIII ${ }^{8}$ do Manuscrito de 1861-1863, ao final das próprias Teorias do Mais-Valor, entre as anotações sobre Jones. Invertendo a ordem, Marx descreve o que chama de "terceira seção", Capital $e$ Lucro:

1) Transformação do mais-valor em lucro. A taxa de lucro em distinção da taxa de mais-valor. 2) Transformação do lucro em lucro médio. Formação da taxa geral de lucro. Transformação dos valores em preços de produção. 3) Teorias de A. Smith e Ricardo sobre lucro e preços de produção. 4) Renda da terra. (Ilustrações das diferenças entre valor e preços de produção.) 5) História da assim chamada lei ricardiana dos rendimentos. 6) Lei da queda da taxa de lucro. A. Smith, Ricardo, Carey. 7) Teorias do lucro. Questão se Sismondi e Malthus devem ser incluídos nas Teorias do Mais-Valor. 8) Divisão do lucro em lucro industrial e juro. O capital mercantil. O capital dinheiro. 9) Renda e suas fontes. Também inserir aqui a questão sobre a relação entre processos de produção e distribuição. 10) Movimentos de refluxo do dinheiro no processo completo da produção capitalista. 11) A economia vulgar. 12) Conclusão. "Capital e Trabalho assalariado". (MEGA, II/3.5, 1861)

Logo em seguida, dois curtos parágrafos depois, Marx elenca os itens da seção primeira, "processo de produção do capital":

\footnotetext{
7 Em alguns manuscritos, redige um índice na página inicial, depois de completa a redação.

8 São vinte e três cadernos no total.
} 
1) Introdução. Mercadoria. Dinheiro. 2) Transformação do dinheiro em capital. 3) O mais-valor absoluto a) Processo de trabalho e processo de valorização. b) Capital constante e capital variável. c) O mais-valor relativo. d) Luta pela jornada de trabalho normal. e) Jornadas de trabalho simultâneas. (Número de trabalhadores empregados simultaneamente.) Montante de mais-valor e taxa de mais-valor. (Grandeza ou quantidade?) 4) O mais-valor relativo. a) Cooperação simples. b) Divisão do trabalho. c) Maquinaria etc. 5) Combinação de mais-valor absoluto e relativo. Relações (proporção) entre trabalho assalariado e mais-valor. Subsunção formal e real do trabalho sob o capital. Produtividade do capital. Trabalho produtivo e improdutivo. 6) Reconversão do mais-valor em capital. A acumulação primitiva. Teoria colonial de Wakefield. 7) Resultado do processo de produção. Pode ser apresentado ou em sub-6) ou em sub-7) A mudança na aparência da lei de apropriação. 8) Teorias do mais-valor. 9) Teorias sobre trabalho produtivo ou improdutivo. (Ibidem.)

No caso da terceira seção, embora a enumeração seja bastante indicativa, chama a atenção a inclusão do item "Capital e trabalho assalariado" ao final, como parte da conclusão, elemento diverso do plano de 1861, citado acima. Ali está também a "renda da terra". Parece claro que Marx trabalha então com o projeto dos seis livros, a indicar aqui "seções", que se tornarão os livros conhecidos. É o entendimento de Rosdolsky (2001, 30 e ss.), para quem a renda da terra parece entrar aqui apenas em ligação com o tema de valor e preço de produção, enquanto o plano da primeira seção nada diz sobre "o salário e suas formas", como ocorrerá no livro primeiro. Também, nada é dito sobre crédito e capital por ações, o que o leva a concluir que o plano dos seis livros ainda estava mantido. ${ }^{9}$

Se o plano em seis livros valia formalmente, parece estar delineado aqui o plano analítico do capital, como totalidade que mantém

9 Cita também várias menções de Marx, nas Teorias do Mais-Valor, aos tais livros, o que nada demonstra, já que os planos se encontram no final do livro. 
e explica as demais categorias. Como já se disse, diante de todo o encadeamento que vai da mercadoria ao capital e do capital aos capitais em particular, nada escapa a esse modo de ser, sendo descabida a tematização em separado de terra e trabalho, sobretudo quando se consideram as formas de renda. Em segundo lugar, a ausência de crédito e ações no plano não indica que seriam tratados em nenhum outro livro. Estavam, no plano original, no próprio livro do capital. De todo modo, o plano é insuficiente, porque Marx não podia ir além do que dispunha, mas é revelador que as duas seções sejam agora tão elaboradas, incompatíveis com o livro sobre o capital previamente planejado.

Além disso, quanto ao plano da primeira seção, diferentemente da terceira seção planejada, ele se mostra mais consistente, naturalmente, pois a matéria estava muito mais bem desenvolvida. Marx ainda planejava uma introdução, não devendo se tratar daquela abandonada em 1857, conforme escreveu em Para a Crítica da Economia Política. Fundamental no plano é o descarte da categoria "capital em geral", contraposta aos múltiplos capitais e à concorrência, separados que são nas duas seções planejadas. Subsunção e trabalho produtivo são mencionados exatamente no mesmo lugar em que aparecem no livro I, na exposição sobre mais-valor absoluto e relativo combinados. Por outro lado, a ausência de qualquer seção sobre salário mostra novamente como a tematização ainda não se tinha desenvolvido, tendo as considerações sobre salário e suas formas aparecido, tanto nos Grundrisse como no Manuscrito de 1861-1863, no próprio desenvolvimento sobre mais-valor.

O que deve chamar mais a atenção, no entanto, é o que Marx não diz, ou seja, o silêncio sobre o plano para a segunda seção, a circulação do capital, bastante inconsistente no plano de 1861 . Em verdade, circulação do capital e reprodução apareceram agora, no exame da economia política, em toda a sua complexidade, razão pela qual somente depois Marx vem a elaborar um plano para os temas do livro segundo. Além disso, também não há qualquer referência ou desenvolvimento sobre a acumulação, à maneira que aparecerá no livro primeiro. Dussel (1988: 197), W. Müller (1983: 185), e K. Stude (1983: 210) se esforçam por detectar elementos no Manuscrito de 1861-1863 da tematização marxiana da acumulação, muitas vezes confundindo-os com a reprodução. Tal qual aparece no livro primeiro, como lei geral, ou ao menos, como preocupação relativamente 
autônoma, a acumulação não se encontra no Manuscrito 1861-1863. É tratada apenas como parte da tematização sobre capital e maquinaria, sempre no âmbito do mais-valor relativo. ${ }^{10}$ No plano acima, nota-se a inclusão do item "Reconversão do mais-valor em capital", onde se situará a acumulação. Novamente, o tema era ainda novo, em toda sua complexidade, tendo-se tornado claro exatamente do confronto com Malthus e Sismondi. No caso de Sismondi, Marx hesita em incluir nesse nível da obra planejada, porque ainda não havia tratado de crédito e concorrência. ${ }^{11}$

De todo modo, o exame literal desse plano parece dar razão a Rosdolsky, Marx pareceria trabalhar ainda com o plano dos seis livros. Além disso, o plano também não contém grandes novidades em relação ao plano de 1861, razão pela qual não deve ser lido como uma novidade do Manuscrito em questão. Porém, um ponto escapou a Rosdolsky em sua abordagem: o fato de que, em 1863, já está formada uma teia categorial que não permite a exposição em separado de capital, trabalho assalariado e renda da terra. É preciso uma unidade orgânica na reflexão, centrada precisamente no capital e incompatível, por isso, com a separação dos três livros, sem falar dos demais. Ou por outra, o texto deve ser examinado não naquilo que contém de planejado, de postulação, mas sim de efetivamente pensado. O plano redigido em momento já avançado do texto aparece, assim, como produto de outro plano.

Finalmente, há que se examinar alguns dos aspectos do texto para compreender a lógica, o plano lógico do qual o plano acima é resultado, expressão, organização. Cabe determinar, pois, como aparece, no Manuscrito de 1861-1863, ainda que de modo contingente, a articulação de toda a trama categorial desenvolvida. Isso se detecta em vários momentos, mas um deles merece ênfase: uma seção que pertence e não pertence às Teorias do Mais-Valor, já que se pretende crítica da economia vulgar, mas, ao mesmo tempo, Marx desenvolve nela a questão do fetichismo da mercadoria, não sob a perspectiva da mercadoria, mas partindo do capital. Na seção dedicada à renda e suas fontes, Marx aborda de modo mais detalhado questão que consumirá poucas páginas do livro terceiro de O Capital, qual seja, a alienação (Veräusserlichung) do capital, ou sua forma de fetiche.

${ }^{10}$ MEGA II/3.6, p. 2039 e ss.

${ }^{11}$ Durante a redação das Teorias do Mais-Valor, Marx realmente pretendia seguir a forma de exposição de Para a Crítica da Economia Política, conciliando sua própria teoria com a crítica aos demais autores ao final de cada capítulo. 
A tematização marxiana diz respeito a vários temas ao mesmo tempo, a questão do juro, a questão da renda e sua distribuição, todo o texto desenvolvido em confronto com a economia vulgar e sua crítica superficial da sociedade burguesa.

A aproximação que se faz dessa passagem tem o objetivo de explicitar como, na aparência da sociabilidade do capital, no nível da predominância acabada da produção de mercadorias, Marx pode compreender todo o circuito categorial de sua obra, ainda que muitos pontos se encontrem por considerar e desenvolver com rigor. Nessa altura do texto, pode considerar, ainda de modo indicativo, a questão das classes, com a qual pretendia encerrar sua obra econômica, tema também abordado quando de sua tematização sobre o trabalho improdutivo, no Manuscrito em análise.

Partindo assim da aparência do modo de produção capitalista, de sua superfície, Marx mostra como aparece invertido para seus agentes, de modo fetichista. Ele diz:

A forma da renda e a fonte da renda expressam as relações da produção capitalista na forma a mais fetichista. É sua forma de existência, como aparece na superfície, separada dos nexos ocultos e da mediação dos elos intermediários. Assim, a terra se torna a fonte da renda da terra, o capital, a fonte do lucro e o trabalho, a fonte do salário. A forma distorcida em que a inversão real se expressa, encontra-se naturalmente reproduzida nas percepções dos agentes desse modo de produção. (MEGA II/3.4, 1452).

Os economistas vulgares percebem o modo de produção capitalista do mesmo modo, distorcido, já que traduzem para a linguagem doutrinária, apologética a visão dos capitalistas sobre o próprio sistema, diferentemente da fisiocracia, de Smith e Ricardo, que tentavam compreender a conexão interna dos fenômenos. Assim, por exemplo, o capital portador de juros é o fetiche acabado, fazendo com que a fórmula D-D' substitua a fórmula do capital, D-M-D': o dinheiro parece efetivamente produzir mais dinheiro. Do mesmo modo, a terra parece produzir sua renda, o capital parece obter o lucro a partir da 
troca, não da produção, como se fosse capital mercantil, e o salário parece ser produzido por toda a jornada de trabalho. De todos esses fetiches, o capital portador de juros parece ser o fetiche completo, transforma em mistério todo o processo que parte da mercadoria e vai da transformação do dinheiro em capital, do mais-valor em lucro até o lucro geral: é apenas o dinheiro que cria dinheiro, o valor em expansão, como se as coisas se relacionassem por si, dinheiro e mercadoria que apagam todos os traços de origem. No início e no final do sistema, a mercadoria. Ao final, porém, rica de determinações. Todas as questões que apareciam a propósito da mercadoria como ponto de partida e as condições em que podia ser compreendida são repostas aqui. Aqui, o ponto de partida é o capital, não em seu processo de produção, mas já desenvolvido em suas formas derivadas. Tem-se, com isso, uma instância privilegiada para que se vislumbre como Marx compreendia todo o desenvolvimento de sua obra, como as formas de ser da sociabilidade do capital se articulam em sua lógica interna e como são percebidas por seus agentes.

Nos processos de produção e circulação, D-M-D', o dinheiro ou mercadoria retornam a seu ponto de partida, o capitalista é o proprietário do valor no início, do valor aumentado ao final. Segundo Marx, cada movimento do dinheiro envolve a reprodução, convertendo-se o dinheiro nas diversas mercadorias envolvidas na produção e novamente em dinheiro. No caso do capital portador de juros, o dinheiro não se transforma, apenas muda de mãos. Aqui, o mais-valor já se mostra bastante obscurecido, sua origem é suprimida, já que o juro supõe como formada (dada) a taxa geral de lucro. Apaga-se também todo o processo concreto que faz da mercadoria e do dinheiro capital, já que o prestamista se torna capitalista tão só porque seu dinheiro expressa "propriedade sobre o capital", o dinheiro emprestado aparece como se capital fosse, já que parece criar valor, enquanto esse valor é tão somente a participação do prestamista no mais-valor criado pelo capitalista com a produção, participação estimada a partir da taxa de lucro. O dinheiro do prestamista, portanto, aparece como valor que gera mais-valor para seu proprietário.

De acordo com Marx, a taxa de juro acompanha a taxa de lucro, mas se movem de modo bastante diverso. De fato, a taxa de lucro supõe movimentos de capitais entre setores, decisões de investimento real baseadas em diferenças de preços e custos de produção, a concorrência entre capitais, enquanto a taxa de juro decorre apenas de um 
mercado homogêneo, baseado numa mercadoria simples, o dinheiro. Marx diz: "Enquanto aquilo que no capital produtivo aparece apenas no movimento e na concorrência entre as esferas particulares, como capital comum da classe, realmente ocorre aqui, segundo o impulso, na demanda por capital." (MEGA II/3.4, 1463). Enquanto a formação da taxa geral de lucro é resultado dum processo complexo, que apaga a própria origem do lucro, o processo de geração do mais-valor nos diversos processos particulares, o dinheiro permite que a taxa de juro seja resultado de demanda e oferta duma mercadoria fixa, que possui o mesmo valor em relação a todas as mercadorias. Assim, o capital se torna efetivamente mercadoria, sendo o juro o seu preço, que flutua como em qualquer outra mercadoria. O capital, por isso, se torna mercadoria fixada na forma dinheiro, algo que não ocorre em seu processo de produção, que envolve várias metamorfoses. D-M-D' se converte em D-D' e, assim como o dinheiro oblitera "a diferença das mercadorias como valores de uso, também oblite$\mathrm{ra}$, por isso, a diferença dos capitais produtivos, que compreende as condições de existência dessas mercadorias, a forma particular dos próprios capitais produtivos" (MEGA II/3.4, 1464). O dinheiro era a forma transformada da mercadoria e agora aparece como a forma transformada do capital, que, com isso, adquire sua forma fetichista. Para desenvolver o capital, parte-se de M-D-M, sendo D-D' o seu resultado, enquanto, aqui, D-D' aparece como sujeito.

A economia vulgar ataca o capital portador de juro porque se trata da forma mais próxima da noção comum de capital, como se o dinheiro produzisse mais dinheiro. Ademais, as contradições, mediações envolvidas no capital industrial são apagadas aqui. Essa noção, segundo Marx, não ultrapassa o próprio horizonte burguês, já que estava presente até mesmo na crítica da burguesia em ascensão contra os usurários de então, antes que a própria atividade de crédito fosse integrada à sociabilidade do capital.

Depois de considerar alguns aspectos da transformação do capital mercantil em capital comercial, do período em que o capital mercantil controlava, determinava a produção, até o momento em que a manufatura passa a controlar o comércio, Marx passa a tratar da diferença entre juro e lucro, embora sejam mera participação no mais-valor. A diferença decorre do fato de que o juro aparece imediatamente como capital e, assim, pode representar um título de propriedade sobre esse mesmo capital, independente de sua produ- 
ção, do processo de valorização. Já o lucro aparece como remuneração do capitalista como representante do capital "que trabalha": "O 'juro' é o fruto do capital, na medida em que ele não 'trabalha', funciona e o lucro é o fruto do capital 'que trabalha', que funciona." (MEGA II/3.4, 1472). Juro e renda, ao final, aparecem como rubricas nos custos de produção do capitalista industrial, aparecem como adiantamentos e jamais como deduções do mais-valor. O capitalista industrial, nesse processo, parece trabalhar para o dinheiro e, com isso, o lucro se torna remuneração por seu trabalho, como se tivesse produzido efetivamente para pagar, com uma parte de sua remuneração, o juro do capital.

Com isso, a alienação do capital se manifesta como inversão, em que o dinheiro que não entra de fato na produção parece efetivamente movimentar o capital industrial, e, sem percorrer as metamorfoses da mercadoria, parece produzir seu próprio valor, remunerado que é por ser capital. Assim, o valor gerado na produção parece ser produzido pelos elementos independentes que são antes constituídos por ele. Como se disse, renda e juro parecem ser adiantamentos do capital, são equivalentes para o capitalista industrial que os remunera com o lucro, ainda que não o sejam para o trabalhador que efetivamente os produz. E Marx arremata:

No capital portador de juro - na divisão do lucro em juro e lucro - portanto, o capital obtém sua forma mais reificada, sua forma de puro fetiche e a natureza do mais-valor se representa como perdida. O capital - como coisa - aparece aqui como fonte autônoma do valor; criador de valor do mesmo modo que a terra da renda e o trabalho do salário (em parte como salário, em parte como lucro industrial.) Em verdade, ainda é sempre o preço da mercadoria que deve pagar salário, juro, renda, mas ele os paga porque a terra que nela entra cria a renda, o capital que nela entra cria o juro e o trabalho que nela entra cria o salário; criar essas partes do valor que cabem a seus respectivos proprietários ou representantes, o proprietário da terra, o capitalista e o trabalhador (assalariado e industrial). (MEGA II/3.4, 1497). 
Não é contraditório, acrescenta Marx, que o preço da mercadoria pareça ser determinado por seus componentes, salário, juro, renda da terra e que o preço das mercadorias, por sua vez, determine os rendimentos. É como aparece na realidade, para os agentes envolvidos na produção, ou que participam de seu resultado. Terra, capital e trabalho parecem criar igualmente o valor e, com isso, salário, lucro e renda da terra aparecem como distribuição. Na sociabilidade do capital, todo pressuposto aparece como resultado e todo resultado aparece como pressuposto, de modo que todos os elementos, mesmo o mais simples - a mercadoria -, "apareça como inversão e faça com que as relações entre pessoas apareçam como propriedade das coisas e como relações das pessoas com as propriedades sociais dessas coisas" (MEGA II/3.4, 1505). As relações sociais aparecem para os agentes da produção capitalista, e mesmo para o conjunto da sociedade, como um "mundo encantado", isto é, aparecem como propriedades das coisas, dos elementos materiais da produção.

A mercadoria, portanto, é o ponto de partida da análise, já que é a forma elementar da riqueza na sociedade capitalista. Seu fetichismo, porém, é a forma de manifestação das relações sociais nessa sociedade, o capital aparece como mercadoria e o valor parece ser produzido por essa coisa. Também, os agentes da produção não aparecem do modo como contribuem e agem na produção, mas como classes entre as quais a renda se distribui como remuneração de fatores de produção. A luta de classes, portanto, não pode aparecer para seus participantes como conflito na produção, mas sim na distribuição, onde intervêm não só as próprias classes, mas todas as instâncias que também participam da distribuição. Ademais, as classes ociosas são geradas justamente nesse nível, no nível de distribuição do valor e do mais-valor, pois constituem precisamente forma fenomênica das relações capitalistas, isto é, aparecem na distribuição, na luta de classes, subsumidas, por assim dizer, à lógica do capital, nunca do trabalho.

Não pode causar perplexidade a importância que Rubin conferiu ao fetichismo da mercadoria, eixo de sua obra sobre a teoria marxiana do valor. A tematização da mercadoria e seu fetiche são a compreensão do modo de ser do capital, as coisas apagam as relações sociais de produção e as relações sociais se tornam coisas. Diz Rubin (1980: 61): "A revolução que Marx realizou na Economia Política consiste em ele ter considerado as relações sociais de produção que estão por trás das categorias materiais. É este o verdadeiro objeto de estudo 
da Economia Política enquanto ciência social. (...) As mesmas leis que haviam sido estabelecidas pelos economistas clássicos receberam um caráter e um significado inteiramente diferente, no sistema de Marx."

Esse resultado é fundamental para o próprio desenvolvimento que se seguiu na reflexão marxiana. Marx não concebeu e produziu sua obra como ciência pura, desinteressada, como mera instauração epistêmica. A crítica da economia política se pretende parte da prática, único critério de verdade para Marx. Se abandonou a Ideologia Alemã à crítica roedora dos vermes, não podia fazê-lo aqui, dado o caráter decisivo da empreitada. Assim, explicitar a gênese no percurso da mercadoria e do capital é necessidade não só do objeto, mas também política, compreender a totalidade do capital criticamente é criar armas para a luta em que seu autor estava imerso.

Embora a análise do fetichismo da mercadoria já aparecesse de modo indicativo na obra de 1859,12 no Manuscrito de 1861-1863, o desenvolvimento aparece de modo sintético, mas abrangente, na forma de fetichismo do capital. Foi retomado na redação do esboço do livro terceiro, entre 1864 e 1865, guardando grande semelhança com o texto que o precedeu. Krätke (2001) utiliza essa tematização marxiana para discutir a completude de O Capital, se possui um fim, um encadeamento lógico completo. O próprio Manuscrito aqui analisado permite vislumbrar uma resposta positiva para a questão, ainda que Marx não tenha redigido o texto inteiro, o que certamente implicaria modificações, dado seu procedimento habitual. Fica claro, porém, que conseguiu estabelecer, entre 1857 e 1863, um conjunto de categorias articuladas, que lhe permitiram não só compreender os elementos fundamentais da sociedade capitalista, como também suprassumir a economia política, criticá-la e ao mesmo tempo desenvolvê-la, não sendo descabido afirmar seu vínculo com autores que o precederam. Assim como, somente na sociedade completa, acabada do capital, é possível compreender a mercadoria, somente com a mercadoria plenamente desenvolvida como forma da riqueza, da objetividade humana, forma de ser, pode o pensamento se debruçar sobre ela com eficácia.

${ }^{12}$ Cf. MEGA II/2, p. 113 e ss. Para Rosdolsky (2001: 117), até mesmo a tematização dos Manuscritos de 1844 sobre dinheiro já contém uma abordagem primeira do fetichismo. 
Não se expuseram aqui todos os elementos do pensamento marxiano desenvolvido em curtíssimo espaço de tempo, por sinal, o momento mais difícil de sua vida pessoal, como atestam as mesmas cartas em que registrou o progresso da redação. Porém, há elementos bastantes para sustentar que Marx, ao final da redação do Manuscrito de 1861-1863, além de haver respondido à questão central da economia política de modo contundente, aquela do excedente, tinha vasto material para a redação dos livros do capital, algo que fará, ainda na forma de esboços, nos anos seguintes, até a publicação do livro primeiro em 1867.

Portanto, há que se concordar com Rosdolsky a respeito do plano de 1863, mas deve-se ver além dele: a perspectiva que Marx tinha de sua obra sempre ia além do planejado, o pensamento sempre se concretizou para além da ideação prévia. Rosdolsky (2001, 49) vê na "fórmula trinitária" um avanço, mas a compreende apenas como crítica da economia vulgar, não percebendo que essa crítica, para ser realizada, implica a visão da totalidade a ela subjacente, a crítica da sociedade de classes supõe a crítica da mercadoria e a crítica da mercadoria conduz à crítica do capital, como totalidade que explica todos os momentos, até mesmo o trabalho assalariado e a propriedade da terra.

\section{Os inéditos de 1864 a 1867: elementos para uma nova abordagem}

Rosdolsky pretende que o plano definitivo teria sido estabelecido em 1865 ou 1866, a partir, como se disse, da correspondência de Marx. A publicação recente dos últimos manuscritos do período 1863-1868 pode fornecer alguns indícios sobre o que foi exposto. Primeiramente, Marx redige um manuscrito do qual restou o chamado "Capítulo sexto, inédito" e, em seguida, lança-se na redação duma série de textos relativos aos livros segundo e terceiro. Pode-se afirmar, portanto, que o plano definitivo é bastante anterior a 1865 .

Com efeito, na redação do "Capítulo sexto, inédito", Marx afirma que "Há três coisas a tratar neste capítulo (...)" (MEGA II/4.1, 24). E, mais adiante, diz que a primeira (mercadorias como produto do capital) [deve] "ser colocada ao final, não no começo, porque cons- 
titui a transição para o livro segundo - Processo de Circulação do Capital." (Idem, grifos nossos). Esse manuscrito foi concluído no verão de 1864, portanto, bem antes das cartas dos dois anos seguintes. A genialidade de Rosdolsky consiste em não ter lido nenhum desses manuscritos e conseguido formular hipóteses bastante plausíveis, a ser modificadas agora. O que é fundamental, na verdade, não é a datação propriamente, mas o que ela implica. Marx só retomaria o manuscrito do livro primeiro no início de 1867. Dedica-se, a partir de 1864, a esboçar os livros segundo e terceiro, sendo o esboço do livro terceiro o "principal manuscrito" utilizado por Engels. Ou seja, pode-se afirmar que, em 1863, já havia um plano completo para a redação, com três livros - além do quarto sobre a teoria - que foi seguido por Engels anos depois.

Para o propósito aqui estabelecido, basta mostrar o "plano" seguido por Marx depois de 1863. Em 1864, o manuscrito do livro segundo, chamado Manuscrito I, possui três capítulos. O primeiro, "A circulação do capital", apresenta as seções sobre "As metamorfoses do capital", "Tempo de produção e tempo de rotação" e "Custos de circulação". O segundo, "A rotação do capital", apresenta as seções "Conceito de rotação", "Capital fixo e capital circulante - ciclos de rotação" e "Influência do tempo de rotação na formação do produto e do valor e produção de mais-valor". O terceiro capítulo trata da reprodução. ${ }^{13}$

Ainda em 1864, Marx inicia a redação do livro terceiro. O manuscrito resultante possui sete capítulos, a saber: "Transformação do mais-valor em lucro"; "Transformação do lucro em lucro médio"; "Lei da queda tendencial da taxa geral de lucro no progresso da produção capitalista"; "Transformação do capital-mercadoria e do capital-dinheiro em capital-mercadoria comercial e capital-dinheiro comercial ou em capital mercantil"; "Divisão do lucro em juro e ganho do empresário. (lucro industrial ou comercial.) O capital portador de juros"; "Crédito. Capital fictício"; "Transformação do sobrelucro em renda da terra"; "Rendimentos (Renda) e suas fontes". ${ }^{14}$ Importa pouco o quanto a exposição marxiana nestes anos ainda careceria de nova elaboração, como de fato ocorrerá nos anos posteriores à primeira edição do livro primeiro. Restam ainda alguns elementos a

${ }^{13}$ Cf. MEGA II/4.1, p. 139 e ss. Como se disse, há também a tematização sobre a reprodução no final do Manuscrito de 1861-1863. A reprodução e a acumulação constituem um capítulo à parte na análise dos manuscritos aqui referidos.

14 MEGA II/4.2. 
serem desenvolvidos, outros, simplesmente, mais bem desenvolvidos. Além disso, a pesquisa em torno da economia política a ser avaliada sobre cada tema, a partir desse momento, passa a ser feita em separado, exigindo um novo esforço de pesquisa por parte de Marx.

O que o percurso descrito indica, no entanto, é o fato de que, em 1864, Marx persegue um plano já elaborado de redação. Em suas principais categorias, a estrutura está pronta, carente ainda de desenvolvimento pleno, é verdade. No mínimo, portanto, duas questões podem ser elucidadas, de antemão, com o exame dos textos citados. A primeira, do momento de instauração da crítica da economia política e o plano correlato a ser seguido. A segunda diz respeito à completude categorial da obra marxiana, face à publicação póstuma dos dois últimos livros. Os adiamentos, como resta evidente, decorreram da dificuldade de redação, isto é, do objeto, mas também da intensa atividade política de Marx no período, dedicado que estava à I Internacional. Marx, afinal, não pensava sua obra como apenas científica, mas também revestida de caráter político.

\section{Considerações finais}

A ruptura na trajetória marxiana, sua mudança de nível, deve-se aos três escritos de 1857 a 1863. Aqui se instaura a crítica da economia política. A exposição dos Grundrisse nos mostra Marx ocupado com a lógica hegeliana, brincando com ela e, ao mesmo tempo, tentando adaptá-la à sua obra. Essa preocupação desaparece depois de 1859, no nível do próprio texto. Com efeito, nas obras seguintes, em todas, não se revelam os mesmos modos de abordar a temática, presentes nos Grundrisse, como se Hegel tivesse sido suprassumido na exposição a partir da mercadoria. Esse fato, por si só, não significa, porém, que a houvesse abandonado, nem quando se refere à lógica de exposição no "Posfácio" à segunda edição do livro I. Reichelt (1970: 76 e ss.), v.g., tentou demonstrar a imanência das categorias ao movimento do conceito de capital, do mesmo modo como Hegel desenvolveu sua própria lógica do conceito. Trata de opor reparos, porém, quando se trata da análise histórica que Marx desenvolverá, ou seja, do caráter histórico das categorias de O Capital. 
Do breve exame aqui realizado, não se pode negar peremptoriamente a ligação entre a reflexão marxiana e Hegel. Porém, o risco que se tem corrido sempre é o estabelecimento de uma arbitrária identidade, a mesma que se estabelece, com frequência entre Marx e Ricardo, tomar os conceitos, nomes das coisas pelas coisas mesmas. Diante disso, cabe aqui uma provocação honesta e uma contribuição singela. A lógica hegeliana é a totalidade ideal em processo, enquanto sua Fenomenologia é o movimento real da cultura, desde a unidade mais elementar, a consciência, até o saber absoluto. Sobre essa obra, Marx disse, num dos pequenos textos suplementares da Ideologia Alemã: "As diferenças das coisas são irrelevantes porque a substância é apreendida como autodiferenciação ou porque a autodiferenciação, o diferenciar, a atividade do entendimento é apreendia como essencial. É por isso que Hegel, no interior da especulação, fornece distinções reais, distinções que capturam as coisas." (2007: 541)

Podemos, por exemplo, fazer uma analogia do seguinte talhe: a mercadoria seria a consciência sensível, o valor e o dinheiro, a consciência de si, a razão, o processo de produção, o espírito, o capital, a religião, a renda, o saber absoluto, a consciência de classe. Nessa indicação superficial, desde a unidade elementar até a realização mais universal, todos os elementos guardam relação entre si. Na sociabilidade do capital, naturalmente, todo esse percurso seria invertido, pervertido pela lógica do espírito que a anima, o capital. A aventura da mercadoria, de fato, assemelha-se mais àquela da consciência na história do que à lógica abstrata. Outras tentativas, mais rigorosas, podem ser feitas. Já foram feitas, em verdade. Porém, o erro está na origem: não se pode dizer, arbitrariamente, que Marx tenha escolhido alguns aspectos da lógica de Hegel, ou de sua Fenomenologia para desenvolver sua obra. A lógica foi dada pelo próprio objeto. Se havia semelhanças com a lógica de Hegel, é porque essa última é efetivamente capaz de compreender, captar as coisas, não porque foi efetivamente aplicada por Marx à realidade do capital, invertida e contraditória.

De todo modo, o percurso que nos interessou aqui foi aquele que parte do "método de pesquisa" e resulta no "método de exposição". Pode-se dizer que, entre os dois, existe a construção da lógica do objeto, a "lógica da coisa", fruto da escavação do objeto de pesquisa. Uma vez desvendada essa lógica, Marx pôde-se lançar na redação definitiva de sua obra, vindo a publicar o livro primeiro em 1867. 
Mais ainda, nos anos de 1863 a 1867, tratou de redigir uma série de manuscritos relativos aos livros segundo e terceiro, que comprovam os argumentos aqui apresentados. O percurso, naturalmente, ainda não estava completo naquele momento, talvez fosse até modificado quando da redação definitiva.

\section{Referências}

CHASIN, J. Marx: estatuto ontológico e resolução metodológica. São Paulo: Boitempo, 2009.

DUSSEL, E. Hacia un Marx desconocido. Cidade do México: Siglo Veinteuno, 1988.

HEGEL, G. W. F. Phänomenologie des Geistes. Frankfurt: Suhrkamp, 1983.

KRÄTKE, M. 'Hier bricht das Manuskrpt ab.' (Engels) Hat das Kapital einen Schluss? Teil I’. Beiträge zur Marx-Engels-Forschung - Neue Folge - 2001: Neue Texte, neue Fragen. Zur Kapital-Edition in der MEGA. Hamburgo, p. 7-43. 2001.

MARX, K. ENGELS, F. Gesamtausgabe. Berlim: Dietz, 1976. v. II/1.1.

MARX, K. ENGELS, F. Gesamtausgabe. Berlim: Dietz, 1976. v. II/1.2.

MARX, K. ENGELS, F. Gesamtausgabe. Berlim: Dietz, 1980. v. II/2.

MARX, K. ENGELS, F. Gesamtausgabe. Berlim: Dietz, 1976. v. II/3.1.

MARX, K. ENGELS, F. Gesamtausgabe. Berlim: Dietz, 1979. v. II/3.4.

MARX, K. ENGELS, F. Gesamtausgabe. Berlim: Dietz, 1980. v. II/3.5.

MARX, K. ENGELS, F. Gesamtausgabe. Berlim: Dietz, 1982. v. II/3.6.

MARX, K. ENGELS, F. Gesamtausgabe. Berlim: Dietz, 1982. v. II/4.1.

MARX, K. ENGELS, F. Gesamtausgabe. Berlim: Akademie, 2012. v. II/4.2.

MARX, K. ENGELS, F. A ideologia alemã. São Paulo: Boitempo, 2009.

MARX, K. Para a crítica da economia politica - Manuscrito de 1861 - 1863. Belo Horizonte: Autêntica, 2010.

MARX, K. Das Kapital 1.3. Briefe über das Kapital. Berlim: Dietz Verlag, 2010.

MISES, L. von. Ação Humana. Rio de Janeiro: Instituto Liberal, 1995.

MÜLLER, M. Zur Reproduktions-, Akkumulations- und Krisentheorie von Karl Marx. In: JAHN, W.; MÜLLER, M. (Org.) Der zweite Entwurf des “Kapitals”: Analysen, Aspekte, Argumente. Berlim: Dietz, 1983. cap. 7, p. 183-209.

REICHELT, H. Zur logischen Struktur des Kapitalbegriffs bei Karl Marx. Frankfurt: Europäische, 1970 ROSDOLSKY, R. Gênese e estrutura de O capital de Karl Marx. Rio de Janeiro: EDUERJ: Contraponto, 2001.

RUBIN, I. A teoria marxista do valor. São Paulo: Brasiliense, 1980.

STUDE, K. Zur Entwicklung der Marxschen Bevölkerungstheorie. In: JAHN, W.; MÜLLER, M. (Org.) Der zweite Entwurf des “Kapitals”: Analysen, Aspekte, Argumente. Berlim: Dietz, 1983. cap. 8, p. 210-227. 